\title{
Aspectos etiológicos da deficiência auditiva: uma revisão integrativa
}

\author{
Etiological aspects of hearing loss: a systematic review
}

Aspectos etiológicos de la discapacidad auditiva: una revisión sistemática

Sabrinna Barbosa de Souza ${ }^{1 *}$, Beatriz Moura Araujoํ․ Ana Luiza de Oliveira Rodrigues ${ }^{1}$, Vilma Cristina Pereira Sardinha1, Walérya Gonçalves de Almeida1, Rubens Gabriel Martins Rosa ${ }^{1}$, Franderta Corado Lopes ${ }^{1}$, Aline Silva Reis ${ }^{1}$, Nelzir Martins Costa ${ }^{1}$.

\section{RESUMO}

Objetivo: Descrever e investigar as principais etiologias da perda auditiva. Métodos: Tratou-se de uma revisão de literatura do tipo integrativa, de caráter qualitativa e descritiva. O estudo consistiu na realização de busca de artigos científicos nas plataformas de saúde, publicados em revistas, jornais e livros, nos idiomas inglês e português, publicados entre os anos de 2017 a 2021. Resultados: Na busca bibliográfica, foram encontrados 35 artigos, destes, somente 15 foram selecionadas. Dentre as publicações selecionadas, dois artigos foram do ano de 2021, ambos em língua portuguesa, quatro artigos foram do ano de 2020, sendo em língua inglesa e língua portuguesa, um artigo do ano de 2018 e em língua portuguesa, um artigo do ano de 2017 também em língua portuguesa, três artigos foram do ano de 2016, sendo da língua inglesa e língua portuguesa. Considerações finais: Diante das inúmeras etiologias descritas, reforçou-se a importância do rastreio seja para causas congênitas e não-congênitas com ou sem fatores genéticos associados, com a finalidade de traçar o perfil nosológico da surdez, e assim, colaborar para que políticas de saúde pública sejam adotadas, a fim de minimizar a ocorrência.

Palavras-chave: Surdez, Perda auditiva, Deficiência auditiva.

\begin{abstract}
Objective: To describe and investigate the main etiologies of hearing loss. Methods: This was an integrative, qualitative and descriptive literature review. The study consisted of searching scientific articles on health platforms, published in magazines, newspapers and books, in English and Portuguese, published between the years 2017 to 2021. Results: In the bibliographic search, 35 articles were found, of these, only 15 were selected. Among the selected publications, two articles were from the year 2021, both in Portuguese, four articles were from the year 2020, being in English and Portuguese, one article from the year 2018 and in Portuguese, one article from the year 2017 also in Portuguese, three articles were from the year 2016, being English and Portuguese. Final considerations: In view of the numerous etiologies described, the importance of screening was reinforced, whether for congenital and non-congenital causes with or without associated genetic factors, in order to trace the clinical profile of deafness, and thus collaborate so that public health are adopted in order to minimize the occurrence.
\end{abstract}

Keywords: Deafness, Hearing loss, Hearing impairments.

\section{RESUMEN}

Objetivo: Describir e investigar las principales etiologías de la hipoacusia. Métodos: Esta fue una revisión bibliográfica integradora, cualitativa y descriptiva. El estudio consistió en la búsqueda de artículos científicos en plataformas de salud, publicados en revistas, periódicos y libros, en inglés y portugués, publicados entre los años 2017 a 2021. Resultados: En la bibliografía búsqueda, se encontraron 35 artículos, de estos, solo

${ }^{1}$ Faculdade Presidente Antônio Carlos (FAPAC), Porto Nacional - TO. *E-mail: sabrinnasbds@gmail.com

SUBMETIDO EM: 7/2021

ACEITO EM: 7/2021

PUBLICADO EM: 8/2021 
se seleccionaron 15. Entre las publicaciones seleccionadas, dos artículos fueron del año 2021, los dos en portugués, cuatro artículos fueron del año 2020, estando en inglés y portugués, un artículo del año 2018 en portugués, un artículo del año 2017 también en portugués, tres artículos fueron del año 2016, siendo inglés y portugués. Consideraciones finales: Ante las numerosas etiologías descritas, fue reforzada la importancia del cribado, ya sea por causas congénitas y no congénitas, con o sin factores genéticos asociados, para trazar el perfil nosológico de la sordera, y así colaborar para que el público la salud se adoptan con el fin de minimizar la ocurrencia.

Palabras clave: Sordera, Hipoacusia, Pérdida de audición.

\section{INTRODUÇÃO}

O termo surdez tem sido utilizado para designar qualquer que seja a perda de audição, incompleta ou completa. Atualmente, buscou-se uma nova denominação para a surdez. Surdo é um termo visto como incorreto e depreciativo da situação da pessoa, daí a insistência atual de se usar a palavra "deficiência auditiva" em seu lugar. Em inglês "deafness" tinha o mesmo significado que surdez, sendo trocada atualmente por "hard of hearing" e "deafness" passou a ter o significado de perda de audição profunda, em suma, quando a média das três frequências da fala é maior que 93 dB NA (PIGNATIRI SSN e ANSELMO WT, 2018).

Em sequência, a Organização Mundial de Saúde (2018) analisou, mediante documento expedido por ela, que até 630 milhões dos seres humanos sofrerão com patologia relacionada a prejuízo no aparelho auditivo na estimativa para o ano de 2030. O estudo salientou, entretanto, que cerca de $60 \%$ das consequências auditivas podem ser evitadas com incentivo financeiro em prevenção e tratamento de patologias relacionadas à surdez (FERNANDES FS, 2019)

A comunicação possui um dinamismo bem abstruso, pois envolve formação e reprodução do pensar, admitindo o colóquio entre as pessoas. Um dos mais relevantes enfoques da apresentação auditiva do homem é certamente a sabedoria do dialeto. Diagnóstico e manejo, em crianças deficientes auditivas executados tardiamente, trará danos consistentes no desempenho da linguagem. A perda da audição pode causar comprometimento individual em diversos Âmbitos, assim como afetar a dinâmica interpessoal do indivíduo. (COSTA TN, et al., 2020)

Segundo Jardim DS, et al., (2017), adultos limitam-se em suas atividades cotidianas, sociais, de compreensão de diálogos, afetando sua qualidade de vida; já quando trata-se de idosos, um conjunto de acometimentos é capaz de transformar negativamente suas vidas, tendo em vista que não só a qualidade de vida decai, mas o estado emocional, cognitivo, o comportamento e sua capacidade de sociabilidade com a comunidade e até mesmo com a própria família.

Além disso, acontece um prejuízo na comunicação social, na fala e em várias outras atividades de aprendizado do dia a dia, o que alavanca consequências psicológicas e de desenvolvimento desses indivíduos, uma vez que se analisa, entre os adultos, que a Perda Auditiva (PA) se interliga ao quadro de depressão, ao declínio cognitivo e à redução da capacidade funcional (BARBOSA HJC, et al., 2018).

Algumas das principais causas da perda auditiva poderiam ser evitadas ou suas sequelas diminuídas, se ocorressem precocemente com as crianças medidas de identificação, diagnóstico e reabilitação, utilizandose medidas que contemplassem esquemas vacinais, cuidados quanto à fase de todo o pré-natal, rastreamento e acompanhamento por parte dos profissionais acerca da saúde auditiva. Dito isto, faz-se necessária a precocidade diagnóstica no que tange $o$ aparelho auditivo e as possíveis perdas que neonatos, pré-escolares e escolares possam vir a sofrer. Nesse sentido, o poder público em saúde tem oferecido e atuado tanto no diagnóstico quanto na terapia específica em reabilitação dentro da perda auditiva. (PASSOS LRM e LACERDA ABM, 2017).

As etiologias mais recorrentes da perda auditiva foram intituladas em seis grupos principais: adquiridas no período neonatal; infecção neonatal congênita; genéticas sindrômicas e genéticas não sindrômicas; neuropatia auditiva; indeterminada (após exclusão das outras causas de PA); e outras anomalias de orelha interna e etiologias centrais. (FAISTAUER M, et al., 2019). 
Faistauner M, et al. (2019), afirmaram que o diagnóstico etiológico seja realizado adequadamente e possa contribuir com o manejo e com o prognóstico da deficiência, é necessário que a perda auditiva seja diagnosticada o mais precoce possível. Diversos estudos vêm demonstrando a importância do diagnóstico precoce.

As anomalias de ouvido acontecem na embriogênese e acometem a orelha externa, média e/ou interna. De forma geral, esses defeitos congênitos danificam o pavilhão auricular e o Meato Acústico Externo (MAE), podendo acontecer modificações significativas em dois modos, unilateral ou bilateral (MATOS IL, et al., 2019).

Em relação aos córtex auditivos primários, ele pode ser acometido bilateralmente, diminuindo a sensibilidade do ouvido, levando a surdez completa. Se a destruição for unilateral, existe uma limitação da audição contralateral, não havendo surdez porque existem várias fibras que se intercruzam, e todavia pode acontecer uma perda da capacidade para encontrar a origem do som, visto que para isto são necessários sinais paralelos de ambos os córtex auditivos primários. Quando o problema afeta as áreas de ligação auditiva, o indivíduo perde a capacidade de entender o significado do som ouvido, sendo a agnosia auditiva (PRADA SP, et al., 2019).

Conforme afirmaram Jardim DS, et al. (2016), o público senil e os neonatos não recebem devida atenção tanto quanto a faixa populacional que se encontra trabalhando, a respeito de pesquisas sobre modificações no sistema auditivo, apontado por uma pesquisa epidemiológica voltada para a área realizada no País.

No sistema de saúde, as propostas destinadas às pessoas com prejuízo auditivo não são amplamente difundidas em se tratando de serviço médico, tornando-se um grande malogro nesse cenário. O Sistema Único de Saúde não disponibiliza o teste de Guthrie, sendo requisitado por lei aos recém-nascidos, o teste de emissões otoacústicas. (SCHÜFFNER ROA, et al., 2018).

A deficiência auditiva é um tema inclusivo e de relevância para sociedade, e para os acometidos por essa condição. Portanto, o presente estudo objetivou apresentar uma revisão integrativa acerca das possíveis etiologias da deficiência auditiva a partir de estudos dos últimos cinco anos.

\section{MÉTODOS}

Trata-se de uma revisão de literatura do tipo integrativa, de caráter qualitativa e descritiva, com a finalidade de investigar os aspectos etiológicos da surdez, a partir de estudos realizados no período de 2016 a 2021. A pergunta norteadora da pesquisa foi elaborada de forma clara e objetiva para possibilitar um resultado com o mínimo de viés possível.

Foi estruturada com os seguintes elementos: população ou alvo da pesquisa $(P)$, desfecho $(O)$ e tipo de estudo $(T)$. Neste estudo a pergunta que norteou a revisão foi "Quais são os fatores etiológicos que estão relacionados à surdez?". Desse modo, tem-se a compreensão da etiopatogenia da surdez como alvo da pesquisa $(\mathrm{P})$; as descrições dos fatores desencadeantes relacionados à etiologia da patologia são o desfecho (O); e as pesquisas qualitativas, observacionais e comparativas são os tipos de estudos (T).

O estudo consiste na realização de busca de artigos científicos publicados em revistas, jornais e livros, nos idiomas inglês e português, encontradas nas plataformas Scientific Electronic Library Online (SciELO), PUBMED, Biblioteca Virtual em Saúde (BVS) e Coordenação de Aperfeiçoamento de Pessoal de Nível Superior (CAPES). Utilizaram-se os motores de busca das bases de dados, empregando-se os operadores booleanos "AND" e "OR". Os Descritores em Ciências da Saúde (DeCS) utilizados para a busca dos artigos foram: surdez/ deafness; perda auditiva/ hearing Loss e deficiência auditiva/ hearing impairments.

Foram executadas as seguintes etapas para seleção dos artigos: Elaboração da pergunta norteadora "Quais são os fatores etiológicos que estão relacionados à surdez?"; busca diversificada de artigos de acordo com os critérios de inclusão e exclusão, e a partir dos DeCS, com leitura de resumos e títulos, e posteriormente leitura completa; extração de dados com análise crítica de cada estudo e das características; comparação dos resultados; e por fim, apresentação da revisão em si.

O levantamento bibliográfico foi realizado a partir dos critérios de inclusão, amostragem, objetivo de estudo, tipo de estudo e aqueles que respondem à pergunta norteadora, sendo analisados na língua portuguesa e inglesa. Já os critérios de exclusão foram ano de publicação e local de publicação. 
Para extração dos dados foram utilizados formulários padronizados em planilha do software Excel, sendo coletados dados relativos a: referência bibliográfica, método, objetivo, descrição do estudo, resultados e coleta de dados, conclusões. Os dados foram sintetizados de forma qualitativa, gerando o relatório de revisão.

\section{RESULTADOS}

Durante a busca, foram definidas 15 publicações para serem utilizadas neste estudo. Dentre as publicações selecionadas, 13,33\% (2 artigos) são do ano de 2021, ambos em língua portuguesa, encontrados nas plataformas SciELO e BVS; $26,66 \%$ (4 artigos) são do ano de 2020, sendo 25\% (1 artigo) em língua inglesa e 75\% (3 artigos) língua portuguesa, encontrados nas plataformas BVS, Uptodate, Pubmed e SciELO; $33,33 \%$ (5 artigos) do ano de 2019, sendo 60\% (3 artigos) em língua inglesa e 40\% (2 artigos) em língua portuguesa, encontrados nas plataformas Pubmed e SciELO. Foram 6,66\% (1 artigo) do ano de 2018 e em língua portuguesa e 6,66\% (1 artigo) do ano de 2017 e também em língua portuguesa, encontrados nas plataformas BVS e Pubmed, respectivamente; 13,33\% (2 artigos) são do ano de 2016, sendo um artigo na língua inglesa e outro na língua portuguesa, ambos encontrados na plataforma Pubmed.

A Figura 1 sintetiza a inclusão de estudos identificados durante a busca de acordo com os critérios (amostragem, objetivo de estudo, tipo de estudo, língua portuguesa e inglesa) e através da pergunta norteadora ("Quais são os fatores etiológicos que estão relacionados à surdez?"). Os estudos contiveram suas informações sintetizadas nos tópicos: autor/ano, título do artigo, periódico, tipo de estudo e principais achados, os quais foram apresentados no Quadro 1.

Figura 1 - Fluxograma dos estudos selecionados.

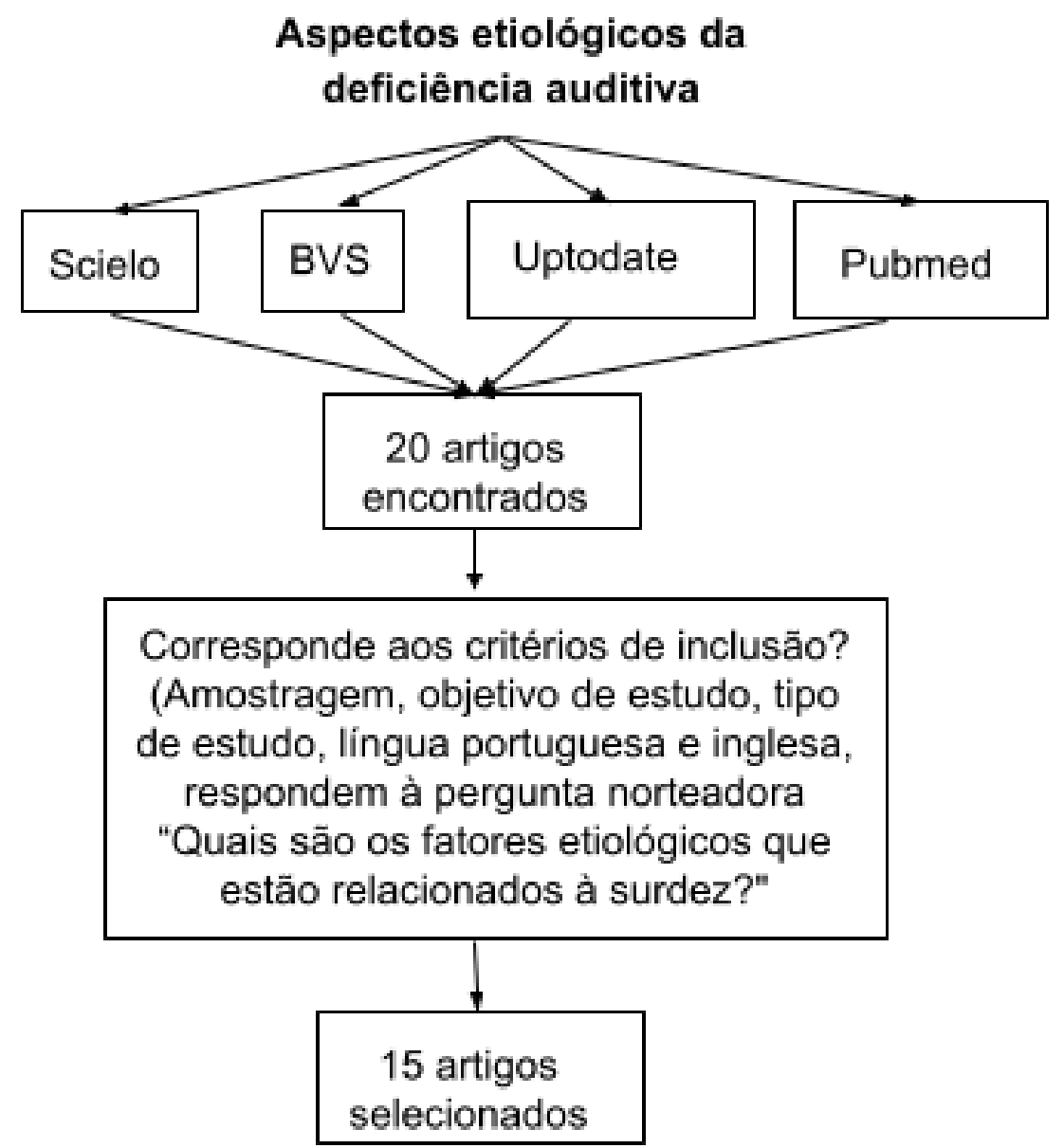

Fonte: Souza SB, et al., 2021. 
Quadro 1 - Quadro sinóptico constituído das publicações analisadas.

\begin{tabular}{|c|c|c|c|c|c|}
\hline $\mathbf{N}$ & Autor (Ano) & Título do Artigo & Periódico & Tipo de estudo & Principais Achados \\
\hline 1 & $\begin{array}{l}\text { SHINAGAWA J, et } \\
\text { al. (2020) }\end{array}$ & $\begin{array}{l}\text { Prevalence and clinical features of } \\
\text { hearing loss caused by EYA4 variants. }\end{array}$ & Scientific reports & Estudo de coorte & $\begin{array}{c}\text { Identificação de novas variantes patogênicas } \\
\text { associadas ao EYA4. }\end{array}$ \\
\hline 2 & $\begin{array}{l}\text { MOHAMMED SH, } \\
\text { et al. (2019) }\end{array}$ & $\begin{array}{c}\text { Association of anemia with } \\
\text { sensorineural hearing loss: a } \\
\text { systematic review and meta-analysis. }\end{array}$ & BMC research notes & $\begin{array}{l}\text { Revisão sistemática } \\
\text { e meta-análise }\end{array}$ & $\begin{array}{c}\text { São necessários mais estudos acerca da ligação } \\
\text { entre ADF e perda auditiva, para chamar a } \\
\text { atenção da saúde pública. }\end{array}$ \\
\hline 3 & $\begin{array}{l}\text { PAIVA CEQ, et al. } \\
(2020)\end{array}$ & $\begin{array}{l}\text { Construção de uma tecnologia em } \\
\text { saúde para identificação de sinais e } \\
\text { sintomas em pacientes surdos. }\end{array}$ & Journal Health NPEPS & $\begin{array}{l}\text { Estudo do tipo } \\
\text { metodológico }\end{array}$ & $\begin{array}{c}\text { Desenvolveu-se uma tecnologia educativa para } \\
\text { a identificação de sinais e sintomas em } \\
\text { pacientes surdos. }\end{array}$ \\
\hline 4 & $\begin{array}{l}\text { BARBOSA HJC, et } \\
\text { al. (2018) }\end{array}$ & $\begin{array}{l}\text { Perfil clínico epidemiológico de } \\
\text { pacientes com perda auditiva. }\end{array}$ & $\begin{array}{c}\text { Journal of Health \& Biological } \\
\text { Sciences }\end{array}$ & $\begin{array}{l}\text { Estudo } \\
\text { observacional } \\
\text { transversal } \\
\text { retrospectivo }\end{array}$ & $\begin{array}{c}\text { A perda auditiva neurossensorial foi a mais } \\
\text { prevalente, a hipoacusia e o zumbido foram } \\
\text { mais frequentes. }\end{array}$ \\
\hline 5 & $\begin{array}{l}\text { SCHIEFFER KM, } \\
\text { et al. (2017) }\end{array}$ & $\begin{array}{c}\text { Associação de anemia por deficiência } \\
\text { de ferro com perda auditiva em adultos } \\
\text { nos EUA. }\end{array}$ & $\begin{array}{c}\text { JAMA Otolaryngology-Head \& } \\
\text { Neck Surgery }\end{array}$ & $\begin{array}{l}\text { Estudo de coorte } \\
\text { retrospectivo }\end{array}$ & $\begin{array}{l}\text { Há uma associação entre IDA em adultos e } \\
\text { perda auditiva, sendo necessário entender } \\
\text { acerca da relação e identificar se o diagnóstico e } \\
\text { o tratamento imediato podem trazer benefícios. }\end{array}$ \\
\hline 6 & $\begin{array}{l}\text { SLOAN-HEGGEN } \\
\text { CM, et al. (2016) }\end{array}$ & $\begin{array}{l}\text { Comprehensive genetic testing in the } \\
\text { clinical evaluation of } 1119 \\
\text { patients with hearing loss. }\end{array}$ & Human genectics & Estudo de coorte & $\begin{array}{l}\text { Testes resultaram na identificação de causa } \\
\text { genética subjacente para a perda auditiva. }\end{array}$ \\
\hline 7 & $\begin{array}{l}\text { CHEN S, et al. } \\
\qquad(2019)\end{array}$ & $\begin{array}{l}\text { The prevalence of deafness-associated } \\
\text { mutations in neonates: A meta-analysis } \\
\text { of clinical trials. }\end{array}$ & $\begin{array}{l}\text { International Journal of Pediatric } \\
\text { Otorhinolayngology }\end{array}$ & Meta-análise & $\begin{array}{c}\text { É preciso refletir acerca do modo de uso da } \\
\text { atual triagem genética para surdez para } \\
\text { amplificar a sua eficácia. }\end{array}$ \\
\hline 8 & $\begin{array}{l}\text { NAGTEGAAL AP, } \\
\text { et al. (2019) }\end{array}$ & $\begin{array}{l}\text { Genome-wide association meta- } \\
\text { analysis identifies five novel loci for } \\
\text { age-related hearing impairment. }\end{array}$ & Scientific Reports & Meta-análise & $\begin{array}{l}\text { Foram encontrados cinco novos loci para } \\
\text { deficiência auditiva relacionada à idade. }\end{array}$ \\
\hline
\end{tabular}




\begin{tabular}{|c|c|c|c|c|c|}
\hline $\mathbf{N}$ & Autor (Ano) & Título do Artigo & Periódico & Tipo de estudo & Principais Achados \\
\hline 9 & $\begin{array}{l}\text { PASSOS LR, et al. } \\
(2021)\end{array}$ & $\begin{array}{l}\text { Audição da Criança: Fatores de Risco, } \\
\text { Sinais e Prevenção da Perda Auditiva. }\end{array}$ & Revista Tuiuti: Ciência e Cultura & $\begin{array}{l}\text { Tipo transversal } \\
\text { quantitativo }\end{array}$ & $\begin{array}{l}\text { O índice de fatores de riscos relatados é } \\
\text { elevado em crianças de } 4 \text { a } 5 \text { anos de idade, } \\
\text { reforçando a necessidade de prevenção. }\end{array}$ \\
\hline 10 & $\begin{array}{l}\text { JARDIM DS, et al. } \\
\qquad(2016)\end{array}$ & $\begin{array}{c}\text { Perfil epidemiológico de uma } \\
\text { população com deficiência auditiva. }\end{array}$ & Revista Cefac & $\begin{array}{c}\text { Perfil } \\
\text { Epidemiológico }\end{array}$ & $\begin{array}{c}\text { Necessidade de realização da Triagem Auditiva } \\
\text { Neonatal para detecção precoce da perda } \\
\text { auditiva e início do processo de } \\
\text { reabilitação para idosos, mães e gestantes. }\end{array}$ \\
\hline 11 & $\begin{array}{l}\text { LAMOUNIER P, et } \\
\text { al. }(2021)\end{array}$ & $\begin{array}{c}\text { Perda auditiva associada a } \\
\text { manifestações neurológicas do } \\
\text { citomegalovírus congênito: relato de } \\
\text { caso. }\end{array}$ & $\begin{array}{l}\text { Brazilian Journal of } \\
\text { Development }\end{array}$ & Relato de caso & $\begin{array}{c}\text { CMV como a causa mais prevalente de surdez } \\
\text { neurossensorial congênita adquirida e da sua } \\
\text { manifestação tardia, reforça a necessidade do } \\
\text { monitoramento auditivo. }\end{array}$ \\
\hline 12 & $\begin{array}{l}\text { GAMA R, et al. } \\
(2020)\end{array}$ & $\begin{array}{l}\text { Doença microvascular cerebral na } \\
\text { surdez súbita neurossensorial } \\
\text { idiopática. }\end{array}$ & $\begin{array}{l}\text { Revista Portuguesa de } \\
\text { Otorrinolaringologia e Cirurgia } \\
\text { de cabeça e pescoço }\end{array}$ & $\begin{array}{l}\text { Observacional } \\
\text { caso-controle } \\
\text { retrospectivo }\end{array}$ & $\begin{array}{l}\text { Elevada prevalência de LSB nos doentes com } \\
\text { SSNI. Correlacionou-se com a existência de } \\
\text { fatores de risco cardiovasculares, assim como } \\
\text { com um pior prognóstico em termos de } \\
\text { recuperação auditiva. }\end{array}$ \\
\hline 13 & $\begin{array}{c}\text { SCHÜFFNER } \\
\text { ROA, et al. (2020) }\end{array}$ & $\begin{array}{l}\text { Molecular study of hearing loss in } \\
\text { Minas Gerais, Brazil. }\end{array}$ & $\begin{array}{l}\text { Brazilian Journal of } \\
\text { Otorhinolaryngology }\end{array}$ & Estudo transversal & $\begin{array}{c}\text { Descreve a investigação molecular de dois } \\
\text { genes relacionados à perda auditiva } \\
\text { na população de Minas Gerais mutação 35delG } \\
\text { e D13S1830. }\end{array}$ \\
\hline 14 & $\begin{array}{l}\text { FAISTAUNER M, } \\
\text { et al. (2019) }\end{array}$ & $\begin{array}{c}\text { Etiologia das perdas auditivas } \\
\text { congênita e adquirida no período } \\
\text { neonatal. }\end{array}$ & $\begin{array}{l}\text { Universidade Federal Do Rio } \\
\text { Grande Do Sul. Faculdade De } \\
\text { Medicina- Programa De Pós- } \\
\text { graduação em Saúde da } \\
\text { Criança e do Adolescente }\end{array}$ & Estudo de coorte & $\begin{array}{c}\text { Período neonatal as etiologias genética e } \\
\text { adquirida foram as mais } \\
\text { prevalentes, seguidas por neuropatia auditiva e } \\
\text { infecção congênita. }\end{array}$ \\
\hline 15 & $\begin{array}{l}\text { PRADA SP, et al. } \\
(2019)\end{array}$ & Surdez Neurossensorial Súbita. & $\begin{array}{l}\text { Mestrado integrado em } \\
\text { Medicina, Faculdade de } \\
\text { Medicina de Lisboa }\end{array}$ & $\begin{array}{l}\text { Revisão } \\
\text { Sistemática }\end{array}$ & $\begin{array}{c}\text { Aborda sobre a etiologia, diagnóstico e } \\
\text { tratamento relacionado a surdez neurossensorial } \\
\text { súbita. }\end{array}$ \\
\hline
\end{tabular}

Fonte: Souza SB, et al., (2021). 
Após a seleção do material, realizou-se a leitura exploratória e análise dos textos, culminando em uma reflexão crítica acerca dos assuntos abordados.

\section{DISCUSSÃO}

A DA é definida pela perda parcial ou total da audição diante de determinadas frequências. De acordo com a Organização Mundial de Saúde, a DA foi definida com a perda auditiva superior a $40 \mathrm{~dB}$ no melhor ouvido auditivo em indivíduos maiores de 15 anos e maior que $30 \mathrm{~dB}$ no melhor ouvido auditivo em crianças e adolescentes de 0 a 14 anos (PAIVA CEQ, et al., 2020). O Supplement to the Joint Committee on Infant Hearing $(\mathrm{JClH})$ incluiu na definição atual de surdez todos os indivíduos que apresentam perdas auditivas congênitas e adquiridas, unilateral e bilateral, e de graus variados, além dos tipos sensorioneural distúrbio do espectro da neuropatia auditiva, condutivo permanente e misto (FAISTAUER M, 2019).

A classificação da Perda Auditiva (PA) pode ser realizada de acordo com sua origem de disfunção identificada pelo exame audiométrico. A PA pode ser classificada em: perda auditiva condutiva (PAC), quando há uma dificuldade de passagem do som através do conduto auditivo externo, membrana timpânica e os ossículos auditivos; perda auditiva neurossensorial (PANS), quando há comprometimento da cóclea ou via de condução entre a orelha interna e o córtex cerebral; e perda auditiva mista (PAM), em que possui a associação dos dois tipos anteriores mencionados (BARBOSA HJC, et al., 2018)

Barbosa HJC, et al. (2018), enfatizaram que isso ocorre devido, principalmente, ao aumento da expectativa de vida, visto que essa condição acomete mais a população com idade igual ou superior a 60 anos, em consequência ao envelhecimento natural associado a comorbidades crônicas como hipertensão arterial, diabetes, reumatismo e outros.

Em comparação, Sloan-Heggen CM, et al. (2016) concordaram ao afirmarem que metade de todos os octogenários apresentam deficiência auditiva. Paiva CEQ, et al. (2020) complementaram ao afirmarem que no Brasil cerca de $6,7 \%$ da população apresenta alguma deficiência severa, e que $5,1 \%$ dos brasileiros possuem algum grau de surdez.

Schuffner ROA, et al. (2020), a partir de um estudo transversal com 53 indivíduos que apresentam PA, constataram que $60,37 \%$ dos entrevistados desconheciam a etiologia de sua DA. Mohammed SH, et al. (2019) complementaram ao afirmar que a DA recebe baixa atenção básica e ainda persiste sendo negligenciada. Isso evidencia a falta de estudos e evidências científicas relacionados à etiologia e patogenia da PA.

Faistauner M, et al. (2019) pontuaram que a PA pode ser dividida em dois grandes grupos: as de causas genéticas e as de causas não genéticas. Enquanto em países desenvolvidos predominam-se causas genéticas relacionadas a PA, em países em desenvolvimento, como o Brasil, observa-se maior predominância de causas não genéticas de PA.

Quanto aos fatores de riscos associados a PA em crianças, Jardim DS, et al. (2016) constataram que os fatores mais frequentes são infecções congênitas, permanência na UTI por mais de 48 horas, uso de drogas ototóxicas e otite média recorrente ou persistente por mais de três meses. Faistauner M, et al. (2019) acrescentaram outros fatores de risco como história familiar de PA permanente na infância, anomalias craniofaciais, distúrbios neurodegenerativos, infecções pós natais, traumas cranioencefálicos, quimioterapia e síndromes que cursam com PA. Dentre as infecções congênitas adquiridas no período gestacional, Passos LR, et al. (2021) destacaram a toxoplasmose, citomegalovírus (CMV), rubéola, sífilis e herpes, que estão intimamente envolvidas com o aparecimento da patologia.

Barbosa HJC, et al. (2018) acrescentaram como fator causal para PA a frequente exposição a ruídos, o qual está associado ao zumbido que se manifesta em até $96 \%$ dos pacientes que apresentam PA. Ademais, observaram que a exposição a ruídos estava relacionada a alterações a curto prazo no sono, disfunção de memória e problemas cardiovasculares. Os autores pontuaram que o dano nas células ciliadas causadas pelo ruído deve-se ao processo oxidante nas células, provocando lesão na cóclea e formação de tecido cicatricial, podendo levar até mesmo PA permanente.

Prada SP, et al. (2019) pontuaram as manifestações otológicas relacionadas à sífilis, sendo elas a hipoacusia neurossensorial simétrica ou assimétrica súbita, associada a vertigem e hipofunção vestibular 
severa. Outro causa viral importante na perda auditiva é o vírus da herpes, através da infecção aguda da cóclea ou reativação viral do gânglio espiral. Os autores desse estudo consideraram que as infecções virais induzem ou aumentam respostas autoimunes por meio do próprio DNA ou RNA viral, ou devido semelhança entre os antígenos virais e do hospedeiro, provocando uma reação imune cruzada.

Similarmente, Lamounier P, et al. (2021) em seu estudo de caso sobre manifestações neurológicas do CMV e sua associação com PA, concluíram que a surdez é a sequela mais frequente, sendo do tipo neurossensorial, afetando até $50 \%$ dos indivíduos sintomáticos e entre 10 a $15 \%$ dos portadores assintomáticos. Nesse caso a perda auditiva se manifesta tardiamente e está relacionada à reativação ou reinfecção viral.

Em concordância Faistauner M, et al. (2019) afirmaram que o CMV é a segunda maior causa de PA em crianças em países desenvolvidos, em que $6-21 \%$ dos recém-nascidos assintomáticos apresentam PA devido a história pregressa de infecção. Diante disso, é evidente a importância do conhecimento da associação da infecção viral e a PA para que seja possível o diagnóstico precoce (LAMOUNIER P, et al., 2021)

O estudo de Schieffer KM, et al. (2017) e Mohammed SH, et al. (2019) evidenciaram a associação da PA com anemia por deficiência de ferro, em que foi comprovado 55\% maior de chance de desenvolverem PA neurossensorial em indivíduos que possuem anemia do que naqueles que não apresentam. Sendo assim, a hipótese desenvolvida seria de que a anemia ferropriva comprometeria o fornecimento de oxigênio aos tecidos, provocando um processo de isquemia na cóclea. Outra hipótese desenvolvida está ligada ao sistema nervoso, em que a deficiência de ferro prejudicaria o metabolismo de neurotransmissores, a mielinização e a síntese de DNA. Dessa forma, os danos provocados à mielina do nervo auditivo ocasionam a PA devido a prejuízos na condução nervosa.

Outro estudo selecionado, Gama R, et al. (2020) identificaram uma associação etiológica entre surdez súbita e doenças microvasculares, em que estabeleceram uma correlação significativa entre lesões da substância branca, identificada na ressonância magnética nuclear, e indivíduos diagnosticados com surdez súbita neurossensorial idiopática. Tal relação é explicada pela presença de fatores de riscos vasculares como hipertensão arterial sistêmica, diabetes mellitus, hábitos tabágicos e dislipidemia.

Outro aspecto que deve ser considerado na etiologia da deficiência auditiva são os fatores genéticos. Os trabalhos de Sloan-Heggen CM, et al. (2016), Chen S, et al. (2019), Shinagawa J, et al. (2020) e Nagtegaal AP, et al. (2019) buscaram analisar essa relação genética com a PA.

Sloan-Heggen CM, et al. (2016) realizaram um estudo de coorte em que 39\% dos 1.119 pacientes participantes da pesquisa foram identificados uma causa genética na PA, na qual 49 genes estavam envolvidos. Os principais genes envolvidos foram GJB2, STRC, SLC26A4 e TECTA, apresentando variações de acordo com a etnia. O gene STRC e GJB2 apresentou maior relação com caucasianos e hispânicos, enquanto em pacientes do Oriente Médio ou asiáticos foi mais comum o diagnóstico GJB2. Porém, em pacientes afro-americanos não houve diagnóstico relacionado ao GJB2.

De forma similar, Chen S, et al. (2019), afirmaram que a mutação no gene GJB2 é a causa genética mais comum em casos de PA neurossensorial não sindrômica. Ademais, acrescentaram que em janeiro de 2018 foram identificadas mutações em 100 genes associados a PA não sindrômica e 47 genes relacionados a PA sindrômica. Dessa forma, evidenciaram a importância da triagem genética desde criança na população, no entanto, por ser de alto custo, faz-se necessário um avanço tecnológico significativo para realizar o rastreamento de forma eficaz com um custo razoável. Além disso, permitiram aprofundar o conhecimento a respeito da genética relacionada à surdez.

Em concordância, Shinagawa J, et al. (2020), apresentaram um estudo realizado no Japão, em que analisaram 1.334 pacientes que possuem PA não sindrômica autossômica dominante. O estudo identificou 12 novas variantes patogênicas associadas ao gene EYA4, o que estimou uma incidência de 0,90\% de PA associada ao EYA4 em famílias com PA autossômica dominante. Desse modo, reforçaram a importância da triagem genética em busca de diagnosticar os fatores relacionados à patogênese da PA. 
Nagtegaal AP, et al. (2019) identificaram que a presbiacusia, deficiência auditiva relacionada à idade, é altamente poligênica, a qual contribui para uma herdabilidade de aproximadamente $36 \%$ a $70 \%$. Em relação a etnia, afro-americanos apresentaram menor prevalência em comparação a brancos não hispânicos e hispânicos.

A limitação desta revisão sistemática foi a escassez de estudos nacionais a respeito do tema abordado. Em virtude disso, os estudos internacionais foram de suma importância para a produção dessa revisão e complementam de forma significativa para a pesquisa.

\section{CONSIDERAÇÕES FINAIS}

O presente estudo demonstrou a diversidade de aspectos etiológicos que acarretam o comprometimento auditivo, sejam eles de base congênita ou adquirida, que ainda apresentam uma incidência relevante, embora nem sempre relatada. Diante das inúmeras etiologias descritas, reforçou-se a importância do rastreio seja para causas congênitas e não-congênitas, com ou sem fatores genéticos associados. Sendo assim, a caracterização etiológica acurada e atualizada, principalmente no Brasil, irá permitir traçar o perfil nosológico da surdez, e assim colaborar para que políticas de saúde pública sejam adotadas, a fim de minimizar a ocorrência.

\section{REFERÊNCIAS}

1. BARBOSA HJC, et al. Perfil clínico epidemiológico de pacientes com perda auditiva. Journal Health Biol Sci \& Biological Sciences; Revista de Saúde e Ciências Biológicas., 2018; 6(4): 424-430.

2. CHEN S, et al. The prevalence of deafness-associated mutations in neonates: A meta-analysis of clinical trials. International Journal of Pediatric Otorhinolayngology, 2019; 121: 99-108.

3. COSTA TN, et al. O impacto do implante coclear em pacientes com perda auditiva severa: uma revisão bibliográfica. Revista Eletrônica Acervo Científico, 2020; 14: e5499.

4. FAISTAUER M. Etiologia das perdas auditivas congênita e adquirida no período neonatal. Dissertação (Mestrado em Saúde da Criança e do Adolescente) - Universidade Federal do Rio Grande do Sul, Porto Alegre, 2019; 111 p.

5. GAMA R, et al. Doença microvascular cerebral na surdez súbita neurossensorial idiopática. Revista Portuguesa De Otorrinolaringologia E Cirurgia De Cabeça E Pescoço, 2020; 58(3), 131-137.

6. FERNANDES FS. Diversidade na perda auditiva: conhecer para incluir.Revista Científica Multidisciplinar UNIFLU, 2019; 4(2), 318-336.

7. JARDIM DS, et al. Perda auditiva incapacitante: análise de fatores associados. Audiology-Communication Research, 2017; 22: e1765.

8. JARDIM DS, et al. Perfil epidemiológico de uma população com deficiência auditiva. Revista Cefac, 2016; 18(3): 746757.

9. LAMOUNIER P, et al. Perda auditiva associada a manifestações neurológicas do citomegalovírus congênito: relato de caso. Brazilian Journal of Development, 2021; 7(3): 26306-26313

10. MATOS IL, et al. Análise da percepção da fala com uso de dispositivos de amplificação em indivíduos com malformação de orelha e perda auditiva unilateral. CoDAS, 2019; 32(4):e20190047.

11. MOHAMMED SH, et al. Association of anemia with sensorineural hearing loss: a systematic review and meta-analysis. BMC research notes, 2019; 12(1): 283.

12. NAGTEGAAL AP, et al. Genome-wide association meta-analysis identifies five novel loci for age-related hearing impairment. Scientific Reports, 2019; 9: 15492.

13. PAIVA CEQ, et al. Construção de uma tecnologia em saúde para identificação de sinais e sintomas em pacientes surdos. Journal Health NPEPS, 2020; 5(2): 303-316.

14. PASSOS LRM, LACERDA ABM. Audição da Criança: Fatores de Risco, Sinais e Prevenção da Perda Auditiva. Tuiuti: Ciência e Cultura, 2017; 4(54): 23-38.

15. PIGNATIRI SSN, ANSELMO WT. Tratado de otorrinolaringologia. 3nd ed. Rio de Janeiro: Elsevier, 2018; 533-534 p.

16. PRADA, SP. Surdez neurossensorial súbita. Tese (Doutorado em Medicina) - Faculdade de Medicina de Lisboa. Universidade de Lisboa, Lisboa, 2019; 24p.

17. SCHIEFFER KM, et al. Association of iron deficiency anemia with hearing loss in US adults. JAMA OtolaryngologyHead \& Neck Surgery, 2017; 143(4): 350-354.

18. SCHÜFFNER ROA, et al. Molecular study of hearing loss in Minas Gerais, Brazil. Brazilian Journal of Otorhinolaryngology, 2020; 86(3): 327-331.

19. SHINAGAWA J, et al. Prevalence and clinical features of hearing loss caused by EYA4 variants. Scientific reports, 2020; 10(1): 1-10.

20. SLOAN-HEGGEN CM, et al. Comprehensive genetic testing in the clinical evaluation of 1119 patients with hearing loss. Human genectics, 2016; 135(4): 441-450. 